\title{
Digestibilidade in vitro da Matéria Seca, Nitrogênio e Fibra em Detergente Ácido de Dietas Completas Contendo Farelo de Algodão, Uréia ou Amiréia
}

\author{
Jane Maria Bertocco Ezequiel ${ }^{1}$, Weber Vilas Boas Soares ${ }^{2}$, José Renato Caleiro Seixas ${ }^{3}$
}

\begin{abstract}
RESUMO - Este trabalho foi desenvolvido com o objetivo de avaliar o efeito da suplementação com farelo de algodão, uréia ou amiréia a dietas com silagem de milho e milho moído, por intermédio do método da digestibilidade in vitro da matéria seca, nitrogênio e fibra em detergente ácido. O tratamento com uréia apresentou resultados superiores ao demais tratamentos, em todas características estudadas, e os tratamentos com farelo de algodão ou amiréia, resultados semelhantes. Os valores digestibilidade in vitro obtidos foram: 70,5; 69,8 e 72,7\% para matéria seca; 61,6; 63,1 e 66,7\% para nitrogênio e 30,8; 30,0 e 43,1\% para fibra em detergente ácido dos tratamentos contendo farelo de algodão, amiréia e uréia, respectivamente. As dietas com silagem de milho e milho moído suplementadas com uréia fornecem bons resultados de digestibilidade in vitro de matéria seca, nitrogênio e fibra em detergente ácido
\end{abstract}

Palavras-chave: amiréia, digestibilidade in vitro, farelo de algodão, fibra em detergente ácido, nitrogênio, uréia

\section{In Vitro Disappearance of Dry Matter, Nitrogen and Acid Detergent Fiber of Diets Containing Cottonseed Meal, Urea or Starea}

\begin{abstract}
This work was carried out to evaluate the effect of cottonseed meal, urea or starea supplementation to corn silage and ground corn based diets by In vitro disappearance of dry matter, nitrogen and acid detergent fiber method. The treatment with urea presented better results than the other treatments in all studied characteristics, and the treatments with cottonseed meal or starea presented similar results. The observed In vitro disappearance values were: $70.5,69.8$ and $72.7 \%$ for dry matter, $61.6,63.1$ and $66.7 \%$ for nitrogen and 30.8, 30.0 and $43.1 \%$ for acid detergent fiber for the treatments with cottonseed meal, starea and urea, respectively. The corn silage and ground corn diets supplemented with urea showed good in vitro disappearance of dry matter, nitrogen and acid detergent fiber results.
\end{abstract}

Key Words: acid detergent fiber, cottonseed meal, in vitro disappearance, protein, starea, urea

\section{Introdução}

A uréia é totalmente solúvel no rúmen, sendo prontamente transformada em amônia, a qual fica disponível para ser utilizada na síntese da proteína microbiana. A síntese protéica a partir de fontes de nitrogênio não-protéico (NNP) é uma característica dos ruminantes, os quais possuem microbiota capaz de combinar amônia (forma de nitrogênio mais utilizada pelos microorganismos ruminais para a síntese protéica microbiana) com cadeias carbônicas (provenientes da degradação de fontes energéticas fornecidas na dieta), originando os aminoácidos constituintes das suas proteínas, as quais são degradadas e absorvidas no intestino delgado (NITROFÉRTIL, s.d.).

CAMPOS e RODRIGUES (1985) concluíram que a fonte de energia é fator limitante para a utilização da uréia e a eficiência de uso da amônia, pelos microorganismos ruminais é otimizada quando a uréia é acrescida em dietas com baixo nível protéico e elevado nível de energia, minerais e outros nutrientes que aumentam a atividade microbiana. SATTER e SLYTER (1974) verificaram que, quando a concentração de amônia ruminal foi menor que $50 \mathrm{mg} / \mathrm{L}$, foi necessário suplementação na alimentação dos animais com NNP para o bom desenvolvimento microbiano. A uréia é uma fonte protéica comumente utilizada nas dietas dos ruminantes e tem sido recomendada por vários pesquisadores como fornecedora do NNP, visando melhor aproveitamento das pastagens. $\mathrm{O}$ farelo de algodão é um componente amplamente utilizado nas formulações que visam suplementar os volumosos em sistemas de criação mais intensivos. A alta solubilidade ruminal apresentada pela uréia pode conduzir à toxicidez e baixo consumo. Uma forma de minorar esse problema é o emprego de complexos de liberação lenta da uréia (OWENS e ZINN, 1988). Outra solução, ainda dependente dos

\footnotetext{
${ }^{1}$ Professora do Departamento de Zootecnia - FCAVJ/UNESP - Via de Acesso Prof. Paulo D. Castellane, s/nº. E-mail: janembe@fcav.unesp.br ${ }^{2}$ Pós-Graduando da FCAVJ/UNESP.

3 Zootecnista, Gerente das Rações Fri-Ribe S/A, Pitangueiras. E.mail: joserenato@sp.fri-ribe.com.br
} 
custos de produção, é a amiréia, produto da extrusão do amido com a uréia, que tem reduzido a solubilidade ruminal (SILVA, 1999; CARMO et al., 1999; EZEQUIEL et al., 2000). MANSFIELD et al. (1994) relataram que a fermentação ruminal pode ser limitada pela disponibilidade de energia ou proteína, e não pela inadequada sincronização de liberação desses nutrientes. No entanto, quando a velocidade de fermentação é elevada, ocorre produção e absorção excessivas de nitrogênio amoniacal $\left(\mathrm{N}-\mathrm{NH}_{3}\right)$, aumentando a absorção de nitrogênio (N) e o gasto de energia para excreção da uréia (RUSSELL et al, 1992). Assim, a extrusão poderá ser um método padrão na produção de suplementos protéicos não degradáveis no rúmen (FERBET, 1991).

Com base nesses conhecimentos, este trabalho foi conduzido com o objetivo de verificar a influência da utilização do farelo de algodão, da uréia ou da amiréia como fontes de N na DIVMS, PB e fibra de dietas com silagem de milho e milho moído.

\section{Material e Métodos}

\section{Animais e alimentos}

Foram utilizados dois bovinos da raça Holandesa, machos inteiros, com aproximadamente um ano de idade e peso médio $210 \mathrm{~kg}$, fistulados no rúmen e com cânulas permanentes de 2 polegadas.

Como fonte de volumoso, foi utilizada silagem de milho e como concentrado, mistura de milho moído e farelo de algodão, uréia ou amiréia. Na Tabela 1 , encontra-se a composição químico-bromatológica dos alimentos utilizados.

\section{Tratamentos}

Foram balanceadas três dietas para ganho de $680 \mathrm{~g} / \mathrm{dia}$, todas com a relação volumoso:concentrado de 63:37 (Tabela 1), introduzindo-se farelo de algodão, uréia ou amiréia como fonte suplementar de N. O concentrado e a silagem foram fornecidos duas vezes ao dia, $60 \%$ do total pela manhã e $40 \%$ à tarde, e

Tabela 1 - Composição químico-bromatológica dos ingredientes utilizados, suas proporções nas dietas e composição das dietas (\%MS)

Tabel 1 - Chemical composition of the used ingredients, their proportion in the diets and percentage composition of the diets (\% DM)

\begin{tabular}{|c|c|c|c|}
\hline \multirow[t]{3}{*}{ Item } & \multicolumn{3}{|c|}{$\begin{array}{l}\text { Composição químico-bromatológica dos ingredientes } \\
\text { Chemical composition of ingredients }\end{array}$} \\
\hline & $\mathrm{PB} \%$ & & FDA \\
\hline & $C P \%$ & & $A D F \%$ \\
\hline Silagem de milho (Corn silage) & 7,1 & & 31,4 \\
\hline Milho (Corn) & 10,0 & & 3,4 \\
\hline Farelo de algodão (Cottonseed meal) & 35,1 & & 17,0 \\
\hline Amiréia (Starea) & 38,8 & & 8,1 \\
\hline \multirow[t]{2}{*}{ Uréia (Urea) } & 281,2 & & - \\
\hline & \multicolumn{3}{|c|}{$\begin{array}{l}\text { Propoção nas dietas } \\
\text { Proportion in the diets }\end{array}$} \\
\hline $\begin{array}{l}\text { Ingrediente } \\
\text { Ingredient }\end{array}$ & $\begin{array}{c}\text { Amiréia }^{*} \\
\text { Starea }^{*} \\
\% \\
\end{array}$ & $\begin{array}{c}\text { Farelo de algodão } \\
\text { Cottonseed meal } \\
\%\end{array}$ & $\begin{array}{c}\text { Uréia }^{+} \\
\text {Urea }^{+} \\
\%\end{array}$ \\
\hline Silagem de milho (Corn silage) & 63 & 63 & 63 \\
\hline Milho (Corn) & 21,6 & 21,6 & 35,7 \\
\hline Farelo de algodão (Cottonseed meal) & & 15,4 & \\
\hline Amiréia (Starea) & 15,4 & & \\
\hline \multirow[t]{2}{*}{ Uréia (Urea) } & & & 1,3 \\
\hline & \multicolumn{3}{|c|}{$\begin{array}{l}\text { Composição químico-bromatológica das dietas } \\
\text { Chemical composition of diets }\end{array}$} \\
\hline$\% \mathrm{~PB}(\% C P)$ & 12,6 & 12,0 & 12,0 \\
\hline$\% \mathrm{FDA}(\% A D F)$ & 22,8 & 26,0 & 21,0 \\
\hline
\end{tabular}

+Uréia $=45 \% \mathrm{~N},{ }^{*}$ Amiréia $=7,5 \%$ uréia 
pesadas as sobras pela manhã seguinte, ajustando-se o fornecimento de maneira a haver sobras de aproximadamente $20 \%$ do total fornecido. Sal mineralizado ${ }^{1}$ e água foram fornecidos à vontade. Os animais permaneceram em baias individuais, providas de bebedouro, comedouro e cochos de sal também individuais.

Os bovinos doadores de líquido ruminal foram adaptados à dieta por 21 dias. Na tarde do dia anterior à coleta das amostras do conteúdo ruminal e amostragem do fluído, foi retirado todo alimento dos cochos. As amostras do conteúdo ruminal de cada animal foram coletadas na manhã seguinte com auxílio de bomba à vácuo, perfazendo $600 \mathrm{~mL}$ de fluído/ animal, sendo coadas em dois panos de queijo, para a obtenção somente do fluído, as quais foram devidamente guarnecidas em garrafas térmicas, previamente identificadas e aquecidas com água a $39-40^{\circ} \mathrm{C}$. O fluido foi imediatamente levado ao laboratório, onde foi iniciada a incubação, segundo a técnica de dois estádios de TILLEY e TERRY (1963).

\section{Análises laboratoriais e estatísticas}

Terminada a incubação, os conteúdos de cada tubo foram levados para a determinação da matéria seca (MS), N (PB) e fibra em detergente ácido (FDA), para se proceder aos cálculos dos coeficiente de digestibilidade in vitro das variáveis citadas.

Utilizou-se o delineamento em blocos casualisados com três tratamentos (dietas), dois blocos (animais) e doze repetições dentro de cada bloco (tubos de ensaio), para cada variável estudada, por intermédio do programa estatístico STATGRAPHICS PLUS 6.0, segundo o modelo: $\mathrm{Y}_{\mathrm{ijk}}=\mu+. \mathrm{T}_{\mathrm{i}}+\mathrm{B}_{\mathrm{j}}+\mathrm{e}_{\mathrm{ijk}}$, em que $\mu$ é a média geral; $T_{i}$, o efeito do tratamento $i ; B_{j}$, o efeito do bloco $\mathrm{j} ; \mathrm{e}_{\mathrm{ijk}}$, o efeito do erro experimental. As médias foram comparadas pelo teste Tukey.

\section{Resultados e Discussão}

$\mathrm{Na}$ Tabela 2 encontram-se os resultados da DIVMS e do N (DIVN). Não houve diferença estatística para a DIVMS entre os tratamentos contendo farelo de algodão e amiréia, mas ambos apresentaram resultados inferiores $(\mathrm{P}<0,05)$ ao tratamento com uréia. Entretanto, todos os tratamentos forneceram resultados de digestibilidade acima de $68 \%$. A ingestão
Tabela 2 - Digestibilidade in vitro da matéria seca, nitrogênio e fibra em detergente ácido das dietas

Table 2 - Dry matter, nitrogen and acid detergent fiber digestibility of diets

\begin{tabular}{|c|c|c|c|}
\hline \multirow[t]{4}{*}{$\begin{array}{l}\text { Dietas } \\
\text { Diets }\end{array}$} & \multicolumn{3}{|c|}{$\begin{array}{c}\text { Coeficientes de digestibilidade in vitro } \\
\text { Coefficients of in vitro disappearance }\end{array}$} \\
\hline & MS & $\mathrm{N}$ & FDA \\
\hline & $D M$ & & $A D F$ \\
\hline & $\%$ & $\%$ & $\%$ \\
\hline \multirow{2}{*}{ Farelo de algodão } & $70,5^{b}$ & $61,6^{b}$ & $30,8^{b}$ \\
\hline & & & \\
\hline \multirow{2}{*}{$\begin{array}{l}\text { Cottonseed meal } \\
\text { Amiréia } \\
\text { Starea }\end{array}$} & $69,8^{b}$ & $63,1^{b}$ & $30,04^{\mathrm{b}}$ \\
\hline & & & \\
\hline Uréia & $72,7^{\mathrm{a}}$ & $66,7^{\mathrm{a}}$ & $43,1^{\mathrm{a}}$ \\
\hline \multicolumn{4}{|l|}{ Urea } \\
\hline $\mathrm{CV}(\%)$ & 2,0 & 4,6 & 8,7 \\
\hline
\end{tabular}

${ }^{1}$ Médias, na mesma coluna, seguidas de mesma letra não diferem pelo teste Tukey.

1 Means, within a column, followed by the same letter do not differ by Tukey test.

média dos tratamentos foi de 3,$2 ; 3,0 ;$ e $3,5 \%$ do peso vivo para os tratamentos com farelo de algodão, uréia e amiréia, respectivamente. Supõe-se que a variação no consumo observada possa ter sido influenciada pela maior palatabilidade do farelo de algodão e da amiréia, em relação aos resultados obtidos com o tratamento com uréia., assim como ao efeito da extrusão, como um processo à parte, utilizando-se ou não a uréia nesse processo. REDDY et al. (1981) utilizaram o farelo desengordurado de salseed extrusado com uréia, obtendo um produto semelhante à amiréia, a Saluréia 50 e 70, com 15 e 22,5\% de uréia, respectivamente, e encontraram efeito pronunciado da extrusão sobre a digestibilidade. TURNER et al. (1994) estudaram o milho e o sorgo extrusado com amônia e verificaram alterações na estrutura e na composição química decorrente da gelatinização do amido no processo de extrusão. O coeficiente de digestibilidade da MS do sorgo tratado foi maior do que o do não-tratado e semelhante ao do milho tratado. Maiores valores de digestibilidade da MS podem levar ao aumento na taxa de passagem e,

\footnotetext{
${ }^{1}$ Fósforo $=65$, Cálcio $=120$, Sódio $=180$, Magnésio $=5$, Enxofre $=25$, Cloro $=276 \mathrm{~g} / \mathrm{kg}$ de sal $;$ Zinco $=4000$, Cobre $=1250$, Manganês $=1000$, Ferro $=1200$, Cobalto $=120$, lodo $=120$, Selênio $=12$, Flúor máximo $=650 \mathrm{mg} / \mathrm{kg}$ de sal.
} 
conseqüentemente, aumento na ingestão.

SALMAN et al. (1997) estudaram, por intermédio de ensaios de digestibilidade in vivo com carneiros, dietas semelhantes às deste ensaio, e obtiveram valores gerais médios de digestibilidade da MS mais baixos, mas os resultados obtidos com dietas com amiréia foram superiores $(67 \%)$ às contendo farelo de algodão (64\%) e uréia (64\%). Isto poderia indicar que estudos de digestão in vitro com dietas contendo $\mathrm{N}$ de alta solubilidade ou degradabilidade deveriam ser associadas ao conhecimento da taxa de passagem e conseqüente tempo de permanência no rúmen que as mesmas proporcionam. É importante, portanto, que se descrevam as digestibilidades em vários tempos, e não somente a quantidade degradada em um único tempo. Vale lembrar que o ritmo de degradação varia com o tipo de alimento e, nas condições in vivo, grande parte do $\mathrm{N}-\mathrm{NH}_{3}$ é absorvida pela parede ruminal, ficando indisponível para os microorganismos ao menos temporariamente, a par do processo de reciclagem de $\mathrm{N}$. Nas condições in vitro, poder-se-ia estar otimizando a disponibilidade de $\mathrm{N}-\mathrm{NH}_{3}$ durante grande parte do período de fermentação, o que maximizaria a digestão ruminal.

Os coeficientes de digestibilidade in vitro do $\mathrm{N}$ das dietas (Tabela 2) acompanharam o comportamento obtido para a MS, sem diferenças entre as dietas com farelo de algodão e amiréia, mas ambas foram inferiores $(\mathrm{P}<0,05)$ ao tratamento com uréia. Uma observação a ser feita é que os resultados obtidos, considerando-se os animais, apresentaram diferença de 12 e $7 \%$, respectivamente, para os

tratamentos contendo amiréia e uréia e aquele com para o farelo de algodão, essa diferença foi de apenas 2,5\% ( Tabela 3). O grau de degradação da proteína no rúmen é variável para cada fonte protéica e está altamente correlacionado com a solubilidade protéica. Os resultados da DIVN nesta pesquisa evidenciaram esse efeito. VENS-CAPPEL (1984) verificou que, por si só, o processo de extrusão pode não ter efeito sobre o aproveitamento da proteína e seus aminoácidos nas dietas. Entretanto, FAPOJUWO et al. (1987) estudaram o efeito da extrusão de duas variedades de sorgo com 0,2 e $4 \%$ de hidróxido de cálcio comparando diferentes umidades, temperaturas e rotações do parafuso no processo da extrusão e, ao final do experimento, concluíram que a extrusão melhorou a digestibilidade in vitro da proteína do alimento. A temperatura exerceu grande influência nessa melhora, assim como a rotação do parafuso e a umidade. SALMAN et al. (1997), estudando o balanço de $\mathrm{Ne}$ a digestibilidade do $\mathrm{N}$, verificaram que o processo de extrusão do amido com uréia (amiréia 28) não diminuiu as perdas de $\mathrm{N}$ urinário em relação à uréia nãoextrusada, embora a digestibilidade das dietas com amiréia fosse ligeiramente mais elevada.

Quanto às comparações entre os tratamentos uréia e farelo de algodão, outros pesquisadores encontraram superioridade nos resultados de digestibilidade in vivo da PB com dietas contendo uréia em estudos com bovinos (CICONELLI, 1987; SAMPAIO, 1989; COUTINHO FILHO, 1993) e com ovinos (SIQUEIRA, 1979).

$\mathrm{Na}$ Tabela 2, encontram-se os resultados de

Tabela 3 - Médias dos coeficientes de digestibilidade dos dois animais doadores (\%) Table 3 - Digestibility means from the two donors animals (\%)

\begin{tabular}{|c|c|c|c|c|c|c|}
\hline \multirow[t]{2}{*}{$\begin{array}{l}\text { Dieta } \\
\text { Diet }\end{array}$} & \multicolumn{6}{|c|}{$\begin{array}{l}\text { Coeficientes de digestibilidade in vitro }{ }^{1,2} \\
\text { In vitro disappearance coefficients }\end{array}$} \\
\hline & $\begin{array}{c}\mathrm{MS}_{1} \\
D M_{1} \\
\%\end{array}$ & $\begin{array}{c}\mathrm{MS}_{2} \\
\mathrm{DM}_{2} \\
\%\end{array}$ & $\begin{array}{c}\mathrm{N}_{1} \\
\%\end{array}$ & $\begin{array}{c}\mathrm{N}_{2} \\
\%\end{array}$ & $\begin{array}{c}\mathrm{FDA}_{1} \\
A D F_{1} \\
\%\end{array}$ & $\begin{array}{c}\mathrm{FDA}_{2} \\
A D F_{2} \\
\%\end{array}$ \\
\hline $\begin{array}{l}\text { Farelo de algodão } \\
\text { Cottonseed meal }\end{array}$ & 70,0 & 71,1 & 62,4 & 60,9 & 31,4 & 30,2 \\
\hline $\begin{array}{l}\text { Amiréia } \\
\text { Starea }\end{array}$ & 69,7 & 71,1 & 66,6 & 60,9 & 28,6 & 31,8 \\
\hline $\begin{array}{l}\text { Uréia } \\
\text { Urea }\end{array}$ & 72,6 & 72,8 & 68,9 & 64,5 & 41,8 & 44,4 \\
\hline
\end{tabular}

1 Médias do animal doador 1 .

2 Médias do animal doador 2.

1 Means from the animal 1.

2 Means from the animal 2. 
digestibilidade in vitro da FDA, que não diferiram entre as dietas com farelo de algodão e amiréia, sendo, entretanto, ambos inferiores $(\mathrm{P}<0,05)$ aos resultados das dietas com uréia. A diferença obtida considerando-se os animais doadores foi de $11,6 \mathrm{e}$ $4 \%$, respectivamente, para os tratamentos com amiréia, uréia e farelo de algodão (Tabela 3). Os coeficientes de digestibilidade foram baixos, em média, considerando-se os ingredientes das dietas. COUTINHO FILHO et al. (1995) obtiveram valores de digestibilidade da FDA de $37 \%$, ao avaliarem diferentes fontes protéicas em dietas para ovinos. CROOKER et al. (1983) e ARAÚJO et al. (1995) obtiveram coeficiente de digestibilidade aparente da FDA de $39 \%$ para dietas contendo silagem de capim-elefante e concentrados com milho e farelo de soja ou farelo de algodão, mas KUNG JR. e HUBER (1983) obtiveram 50\% para digestibilidade da FDA em dietas com silagem de milho, farelo de soja e milho moído.

A forma nitrogenada $\mathrm{N}-\mathrm{NH}_{3}$, derivada da degradação de compostos nitrogenados no rúmen tem sido pesquisada quanto à sua capacidade de suprir as exigências de $\mathrm{N}$ de bactérias ruminais celulolíticas (MARTIN, 1981; RUSSELL et al., 1992). VONGHIA e CASAMASSIMA (1979) estudaram o efeito da adição de uréia ao concentrado sobre a digestão da fibra. Concluíram que a adição de até $4 \%$ de uréia ocasionou diminuição na digestibilidade da fibra em dietas com relação volumoso:concentrado de 25:75, resultados contrários aos obtidos na Universidade de Cornell. Existem muitas dúvidas sobre quais as concentrações ótimas de $\mathrm{N}-\mathrm{NH}_{3}$ ruminal para maximizar a utilização da fibra dietética, mas aparentemente as três dietas estudadas poderiam não ser satisfatórias, com referência ao nível ótimo de $\mathrm{N}-\mathrm{NH}_{3}$ ruminal. Segundo HOGAN e WESTON (1979), 3,7 g de N são transformados em proteína microbiana a cada $100 \mathrm{~g}$ de matéria orgânica aparentemente digerida no rúmen. No presente ensaio, houve ingestão de 2,2; 2,7 e 2,4 g de $\mathrm{N}$ degradável/100 g de MS degradável no rúmem (considerando-se $70 \%$ da digestibilidade total como degradabilidade ruminal da MS, $80 \%$ de degradabilidade ruminal do $\mathrm{N}$ da amiréia e $100 \%$ para o N-uréia), para os tratamentos com farelo de algodão, amiréia e uréia, respectivamente, indicando baixa proporção de N disponível no rúmen. SEIXAS (1996) obteve resultados de 50,0; 55,7 e 39,6\% para a digestibilidade da fibra em detergente neutro (FDN), respectivamente, para as dietas com farelo de algodão, amiréia e uréia de dietas com essas mesmas formulações fornecidas para ovinos, obtendo, então, menor digestibilidade da FDN para dietas com uréia comparada com amiréia ou farelo de algodão. Considerando-se $30 \%$ de grãos na silagem empregada nesta pesquisa, a real relação volumoso:concentrado seria 40:60, o que poderia tornar a digestibilidade da FDA mais dependente velocidade de passagem do que da quantidade de massa microbiana com atividade celulolítica.

\section{Conclusões}

A utilização da amiréia em dietas com silagem de milho, apesar de ter aumentado a ingestão de MS, não contribuiu para melhorar os coeficientes de digestibilidade in vitro, quando comparados aos resultados obtidos com uréia e farelo de algodão. A alta qualidade dos ingredientes das dietas, que não as fontes de $\mathrm{N}$, possivelmente minimizaram os efeitos que a liberação mais lenta e gradual de uréia no ambiente ruminal poderia proporcionar sobre a digestibilidade da MS, PB e FDA.

Sob os aspectos estudados neste experimento, a amiréia demonstrou ser uma fonte alternativa nitrogenada viável para a suplementação animal, do ponto de vista nutricional.

Outras pesquisas são necessárias para verificar a viabilidade deste suplemento, em especial em dietas contendo volumosos com elevados teores de fibra.

\section{Referências Bibliográficas}

ARAÚJO, G.G.L., SILVA, J.F.C., VALADARES FILHO, S.C. et al. 1995. Efeito da digestibilidade da proteína sobre o consumo, digestão da matéria seca, matéria orgânica e carboidratos estruturais em vacas lactantes. R. Soc. Bras. Zootec., 24(3):371-381.

CAMPOS, O.F., RODRIGUES, A.A. 1985. Uréia para bovinos em crescimento. Coronel Pacheco: EMBRAPA/CNPGL. 42p.

CARMO, F.R.G., EZEQUIEL, J.M.B., GALATI, R.L. et al. Degradabilidade ruminal in situ da matéria seca e proteína bruta da amiréia contendo $25 \%$ de uréia com diferentes granulometrias. In: CONGRESSO DE INICIAÇÃO CIENTÍFICA DA UNESP, 11, 1999, Botucatu. Anais... Botucatu: UNESP, 1999. p.254.

CICONELLI, M.R.O. Influência da retirada da digesta abomasal sobre a ingestão e digestibilidade aparente dos nutrientes de rações com diferentes fontes protéicas. Jaboticabal, SP: UNESP, 1987. 55p. Monografia (Trabalho de Graduação) Faculdade de Ciências Agrárias e Veterinárias de Jaboticabal/ Universidade Estadual Paulista “Júlio de Mesquita Filho", 1987.

COUTINHO FILHO, J.L.V. Estudos de rações compostas por diferentes fontes de nitrogênio através do desempenho e digestibilidade aparente com ruminantes. Jaboticabal, SP: UNESP, 1993. 69p. Dissertação (Mestrado em Zootecnia) - Faculdade de Ciências Agrárias e Veterinárias de Jaboticabal/Universidade Estadual Paulista “Júlio de Mesquita Filho", 1993. 
COUTINHO FILHO, J.L.V., SAMPAIO, A.A.M., EZEQUIEL, J.M.B. et al. 1995. Efeitos de fontes de nitrogênio sobre a ingestão e digestibilidade aparente de diferentes rações. R. Soc. Bras. Zootec., 24(6):1038-1044.

CROOKER, B.A., CLARK, J.H., SHANKS, R.D. 1983. Effects of formaldehyd treated soybean meal on milk yield, milk composition and digestibility in dairy cow. J. Dairy Sci., 66(3):492-504.

EZEQUIEL, J.M.B., CARMO, F.R.G., GALATI, R.L. et al. Degradabilidade ruminal in situ da matéria seca e proteína bruta da amiréia nas formas moída e peletizada contendo diferentes níveis de uréia In: REUNIÓN LATINOAMERICANA DE PRODUCCIÓN ANIMAL, 16, CONGRÉSO URUGUAYO DE PRODUCCIÓN ANIMAL, 3, 2000, Mar del Plata. Seción Nutrición (CD-Rom).

FAPOJUWO, O.O., MAGA, J.A., JANSEN, G.R. 1987. Effect of extrusion cooking on in vitro protein digestibility of sorghum. J. Food. Sci., 42(1):218-219.

FERBET, P.R. 1991. Technological advances could make extrusion an economically feasible alternative to pelleting. Feedestuffs, 63(9):20-21.

HOGAN, J.P, WESTON, R.H. 1979. Phisiology of digestion and metabolism in the ruminant. In: SILVA, J.F.C., LEÃO, M.I. (Eds.) Fundamentos de nutrição dos ruminantes. Piracicaba: Livroceres. p.85-147.

KUNG JR., L., HUBER, J.T. 1983. Influence of non-protein nitrogen and protein of low ruman degradability on nitrogen flow and utilization in lactating dairy cows. J. Dairy Sci., 66(9):1863-1872.

MANSFIELD, H.R., ENDRES, M.I., STERN, M.D. 1994. Influence of non fibrous carbohydrate and degradable intake protein on fermentation by ruminal microorganisms in continuous culture. J. Anim. Sci., 72(9):2464-2467.

MARTIN, L.C. 1981. Effect of level and form of suplement energy and nitrogen on utilization of low quality roughage by sheep. J. Anim. Sci., 53(2):479-84.

NITROFÉRTIL. s.d Uréia petrofértil para alimentação de ruminantes. Rio de Janeiro, JBIG. 47p.

OWENS F.N., ZINN, R. 1988. Metabolismo de la proteina em los rumiants. In: $\mathrm{CHURCH}$, C.D. (Ed.) El rumiante: fisiologia digestiva y nutrición. Zaragoza: Acribia. p.255-282.

REDDY, P.K., RAO, S.B., PRASAD, D.A. 1981. Development and evaluation of extruded deoiled asseed meal urea products (salurea-50 and salurea -70) by in vitro and in vivo methods. Ind. J. Anim. Sci., 5(6):604-610.

RUSSELL, J.B., O'CONNOR, J.D., FOX, D.G. et al. 1992. A net carbohydrate and protein system for evaluating cattle diets: 1. Ruminal fermentation. J. Anim. Sci., 70(11):3551-3561.

SALMAN, A.K., MATARAZZO, S.V., EZEQUIEL, J.M.B. et al. 1997. Estudo do balanço nitrogenado e da digestibilidade da matéria seca e proteína de rações para ovinos, suplementadas com amiréia, uréia ou farelo de algodão. R. Bras. Zootec., 26(1):179-185.
SAMPAIO, A.A.M. Estudo da liberação de nitrogênio amoniacal in vitro e da digestão total e parcial de nutrientes em bovinos alimentados com ração contendo farelo de algodão, levedura e uréia. Jaboticabal, SP: UNESP, 1989. 112p. Tese ( Doutorado em Zootecnia) - Faculdade de Ciências Agrárias e Veterinárias, Universidade Estadual Paulista "Júlio de Mesquita Filho", 1989.

SATTER, L.D., SLYTER, L.L. 1974. Effect of ammonia concentration on rumen microbial protein production in vitro. Br. J. Nutr., 32(2)199-208.

SEIXAS, J.R.C. Estudos das rações suplementadas com amiréia, uréia ou farelo de algodão através do desempenho e digestibilidade aparente com ruminantes. Jaboticabal, UNESP, 1996. Dissertação (Mestrado em Zootecnia) Faculdade de Ciências Agrárias e Veterinárias, Universidade Estadual Paulista "Júlio de Mesquita Filho", 1996.

SILVA, L.D.F. Degradabilidade ruminal da casca de soja e fontes protéicas e seus efeitos nas digestibilidades ruminale intestinal de rações de bovinos. Jaboticabal, SP:UNESP, 1999. 110p. Tese (Doutorado em Zootecnia) - Faculdade de Ciências Agrárias e Veterinárias de Jaboticabal/Universidade Estadual Paulista "Júlio de Mesquita Filho", 1999.

SIQUEIRA, E.R. 1979. Efeito da uréia como fonte de NNP sobre o consumo e digestibilidade em rações de ovinos. R. Soc. Bras. Zootec., 8(4):906-912.

STATGRAPHICS - PLUS. 1992. Statistical graphics sistem by statistical: version 6.0. Cambridge: Graphics Corporation.

TILLEY, J.M.A., TERRY, R.A. 1963. A two stage technique for the in vitro digestion of forage crops. J. Br. Grassl. Soc., 18(2):104-111.

TURNER, N.D., BYERS, S.M., McDONOUGH, C.C. et al. 1994. Use of ammonia pressure/expansion process to enhance corn and sorghum nutrient available. J. Anim. Sci., 72:193 (suppl. 1).

VENS-CAPPEL, B. 1984. The effects of extrusion and pelleting of feed for trout on the digestibility of protein, amino acids and energy and on feed conversion. Acquacult. Eng., 3(1):71-89.

VONGHIA, G., CASAMASSIMA, D. 1979. Use of non-protein nitrogen in diets for sheep. 4. Effect of urea on digestibility of diets with different protein contents. Ann. Fac. Agrar. Univ. Bari, 31:371-389.
Recebido em: $14 / 12 / 99$ Aceito em: 21/09/00 